\title{
Synergistic effects of zinc borate and aluminium trihydroxide on flammability behaviour of aerospace epoxy system
}

\author{
C. Formicola ${ }^{1,3 *}$, A. De Fenzo ${ }^{1,3}$, M. Zarrelli ${ }^{1,3}$, A. Frache $^{2}$, M. Giordano ${ }^{1,3}$, G. Camino $^{2}$ \\ ${ }^{1} \mathrm{IMCB}$ - Institute of Composite and Biomedical Materials, CNR - Research National Council, P E. Fermi 1, Portici \\ 80055 , Italy \\ ${ }^{2}$ Department of Materials Science and Chemical Engineering Politecnico di Torino, Via Teresa Michel 5,15100 \\ Alessandria, Italy \\ ${ }^{3}$ IMAST - Technological District on Polymeric and Composite Materials Engineering, P E. Fermi 1, Portici 80055, Italy
}

Received 5 March 2009; accepted in revised form 3 April 2009

\begin{abstract}
The flame retardancy of mono-component epoxy resin (RTM6), widely used for aerospace composites, treated with zinc borate $(\mathrm{ZB})$, aluminium trihydroxide (ATH) and their mixtures at different concentrations have been investigated by morphological and thermal characterization. Cone calorimeter data reveal that combustion behaviour, heat release rate peak (PHRR) and heat release rate average (HRR Average) of RTM6 resin decrease substantially when synergistic effects of zinc borate and aluminium trihydroxide intervene. Thermogravimetric (TGA) results and analysis of the residue show that addition higher than $20 \% \mathrm{w} / \mathrm{w}$ of $\mathrm{ZB}, \mathrm{ATH}$, and their mixture greatly promotes RTM6 char formation acting as a barrier layer for the fire development. Depending upon the different used flame additives, SEM micrographs indicate that the morphology of residual char could vary from a compact amalgam-like structure, for the RTM6+ZB system, to a granular structure, characterized by very small particles of degraded resin and additive for the ATH.
\end{abstract}

Keywords: thermosetting resins, fire retardancy, zinc borate, aluminium trihydroxide, cone calorimeter

\section{Introduction}

Zinc borate is an effective inorganic flame retardant and it possesses characteristic properties of flame retardancy (FR), smoke suppression, promoting charring, etc. [1, 2] particularly important according to new fire standards. Zinc borate is commonly used as multifunctional flame retardant in combination with other halogenated or halogenfree flame retardant systems to boost FR properties $[3,4]$. Its efficacy depends upon the type of halogen source (aliphatic versus aromatic) and the used polymer. The zinc borate can generally display synergistic effects with antimony oxide in fire retardancy. In the presence of aluminium trihydroxide
(ATH) or magnesium hydroxide $\left(\mathrm{Mg}(\mathrm{OH})_{2}\right)$, this synergy can be augmented significantly [5]. Previous studies [6-11] have demonstrated that there are major advantages in using a combination of zinc borates with other flame retardants in several kinds of polymers (EVA, PVC, Polyamides, etc...). Furthermore, various authors [13-20] analyzed the fire and smoke behaviours of zinc borate and its synergist effect only in thermoplastic systems or in thermosetting bi-component matrices.

In this work, the synergistic effect of zinc borate and aluminium trihydroxide on the flame retardancy, smoke suppression, and thermal degradation behaviour of a monocomponent epoxy resin 
(RTM6) is investigated. The considered epoxy system is widely used in primary and secondary composite structures within the aerospace sector (Arianne 5 and Airbus A380 [12]) for which fire behaviour represents an important feature upon the final application. The fire retardancy of different samples, characterized by various concentrations of each additive and their combinations is exploited by cone calorimeter, TG-DTG and SEM analysis.

\section{Experimental section}

\subsection{Materials and processing}

The epoxy resin used is a commercially available pre-hardened epoxy-amine system labelled RTM6. The system was provided by Hexcel Composites (Duxford, UK). The ultra fine zinc borate $(2 \mathrm{ZnO}$ $\left.3 \mathrm{~B}_{2} \mathrm{O}_{3} 3.5 \mathrm{H}_{2} \mathrm{O}\right)$ and the aluminium trihydroxide $\left(\mathrm{Al}(\mathrm{OH})_{3}\right)$ were supplied respectively by Joseph Storey \& Co. (UK) and by Dadco (UK). The composites were prepared by mixing the epoxy resin with ZB and ATH both separately and in combination. For the separate mixtures 5, 10, 20, 30 and $40 \% \mathrm{w} / \mathrm{w}$ were used while for the combination they were mixed at 1:1 ratio in mass at 10,20, 30 and $40 \% \mathrm{w} / \mathrm{w}$. The mixing was performed by using a Heidolph RZR mechanical stirring equipment. The samples were prepared by mixing RTM6 with ZB and ATH for $10 \mathrm{~min}$ at $1050 \mathrm{rpm}$ and $10 \mathrm{~min}$ at $2000 \mathrm{rpm}$. Obtained mixture was then degassed for $30 \mathrm{~min}$ at $90^{\circ} \mathrm{C}$ under vacuum to eliminate entrapped air and absorbed humidity. The final liquid mixture was then poured in aluminium mould and cured by a two stage temperature profile (160 and $180^{\circ} \mathrm{C}$ respectively for 90 and $120 \mathrm{~min}$ ) according to the curing schedule sheet of the neat epoxy resin. Preliminary TGA scans on neat additives were also performed to evaluate their maximum degradation temperatures. It was found that zinc borate and aluminium trihydroxide degraded respectively at 436 and $299^{\circ} \mathrm{C}$ well below the set curing conditions.

\subsection{Methods}

Cone calorimeter tests were performed using a Fire Testing Technology Ldt. equipment according to the ASTM E1354-04 procedure. Samples, with nominal dimensions of $100 \times 100 \times 7 \mathrm{~mm}^{3}$, were tested horizontally under an incident flux of
$50 \mathrm{~kW} / \mathrm{m}^{2}$. This level was chosen as it corresponds to the evolved heat during a fire. Thermogravimetric analysis was carried out using a TGA 2950 by TA Instruments. All measurements were conducted under nitrogen flow, with a sample weight of about $7 \pm 0.5 \mathrm{mg}$; for each test the heating rate was $10^{\circ} \mathrm{C} / \mathrm{min}$ from ambient to $800^{\circ} \mathrm{C}$. The precision on the temperature measurements during each scan, according to the calibration procedure was $\pm 0.5^{\circ} \mathrm{C}$ in the range $30-400^{\circ} \mathrm{C}$ and $\pm 1{ }^{\circ} \mathrm{C}$ in the range $400-800^{\circ} \mathrm{C}$. SEM and optical micrographs of additive powder, composites and residuals were taken respectively by an 1450VP LEO SEM microscopy and an optical Olimpus BX51 Instruments.

\section{Results and discussion}

\subsection{SEM and optical microscopy}

Multiple locations on different samples were observing by optical and SEM microscopy to verify the level of dispersion. Figure 1 reports a 10X optical micrograph of $20 \% \mathrm{w} / \mathrm{w}$ zinc borate and epoxy system, showing a uniform distribution through the matrix. At all considered concentrations either for $\mathrm{ZB}$ and $\mathrm{ATH}$, the powder is well dispersed into the epoxy matrix maintaining also its original grain size as also confirmed by Figures $2 a$ and $2 b$, where SEM micrographs, respectively of $\mathrm{ZB}$ as-received and RTM6/ZB mixing at 20\% w/w are reported. An appreciable uniformity of filler within the hosting matrix where observed on all loaded samples for both ZB and ATH filler.

In order to study the synergistic effects of zinc borate with aluminium trihydroxide, samples of composite of RTM6 and ZB/ATH, dispersed at

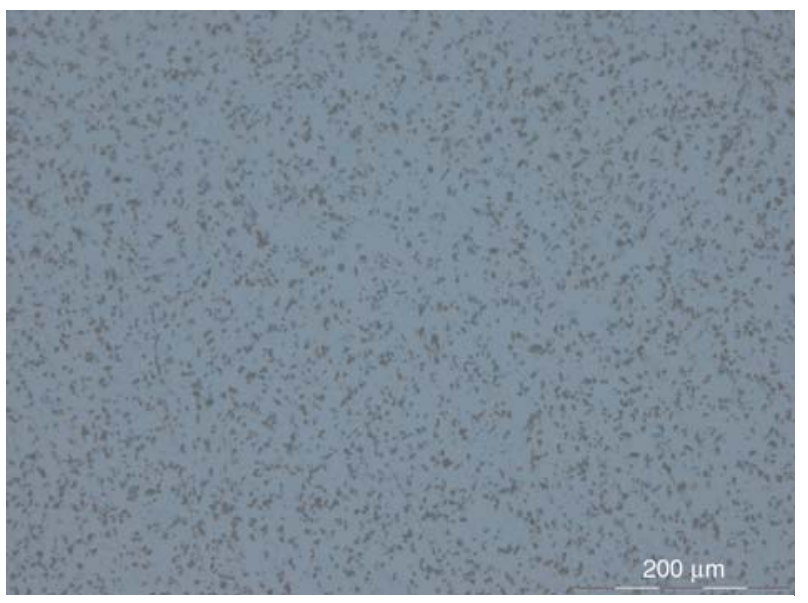

Figure 1. Optical microscopy of zinc borate dispersed into the epoxy resin $(200 \mu \mathrm{m})$ 

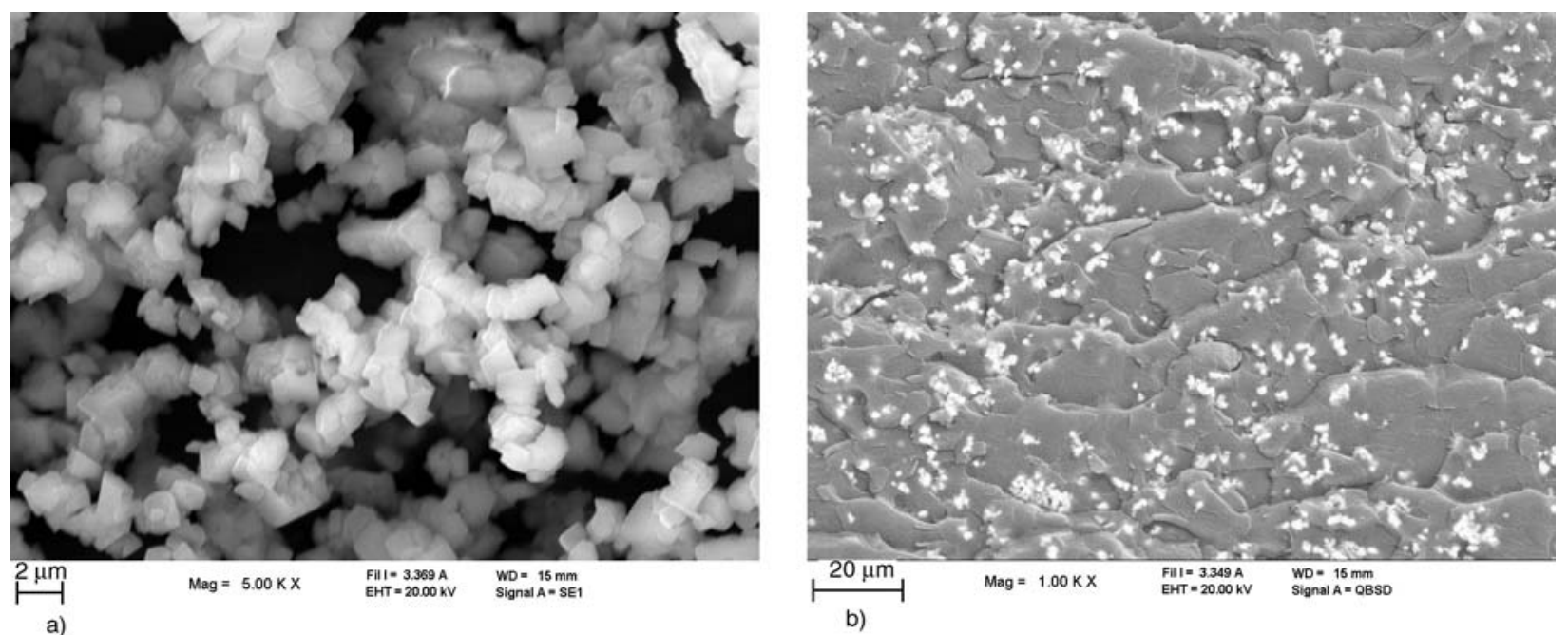

b)

Figure 2. Scanning electron micrograph of zinc borate powder (a) and scanning electron micrograph of composites of RTM6 and ZB 20\% w/w (b)

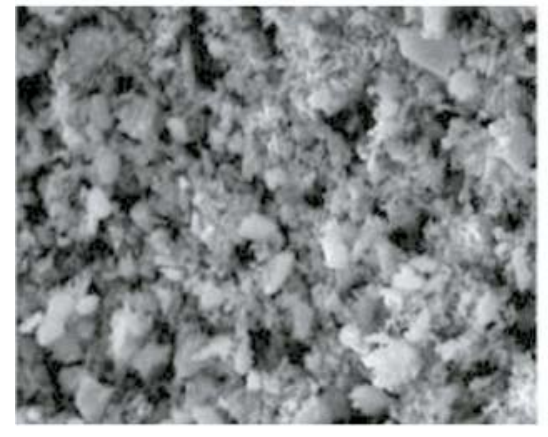

a)

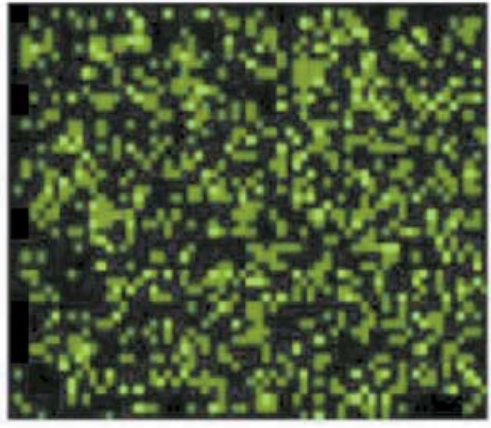

Zink Ka1

b)

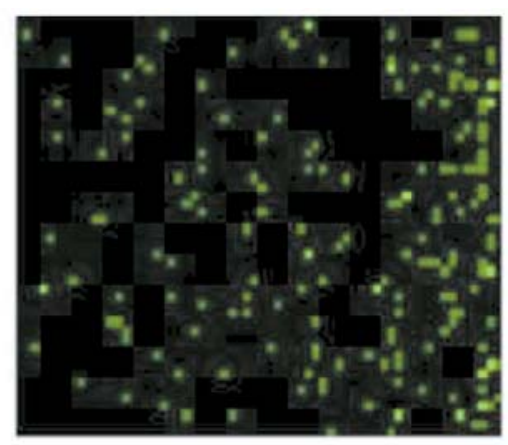

Aluminum Ka1

c)

Figure 3. Mapping of ZB/ATH sample dispersed into the epoxy resin

total concentration of $20 \% \mathrm{w} / \mathrm{w}$, were mapped by SEM. The presence of ZB and ATH, consistently found together within the same area of the sample, lead to the reasonable conclusion that an interaction between the two additives could be assumed (Figure 3). This conclusion is also confirmed by experimental TGA data compared with the corresponding calculated curves as reported in following paragraph.

\subsection{Thermogravimetric analysis}

Thermogravimetric analysis (TGA) and derivative signal (DTG) represent a quantitative methodology useful to analyze the stability of materials. TGA scans were performed on all composite samples for each concentration. TGA theoretical curves (calculated curves) were then computed and compared to experimentally obtained thermographs to further understand the synergist effect of
ZB and ATH on the degradation behaviour of the RTM6 epoxy system.

Analysis of the TGA curves and their DTG signals reveals that onset temperature, which corresponds to the value at $5 \%$ of weight loss, are augmented significantly in the case of 30 and $40 \% \mathrm{w} / \mathrm{w}$ content for both mixtures, RTM6/ATH and RTM6/ZB. According to Table 1, in fact, measured values for onset and maximum temperatures fall within the same range, if the error bar is considered; thus highlighting the substantial inefficiency of the filler to act as flame retardant. As expected, it is neces-

Table 1. TGA values of treated RTM6 with ATH and ZB at different concentrations

\begin{tabular}{|l|c|c|c|c|c|}
\hline \multicolumn{1}{|c|}{ Sample } & $\mathbf{T}_{\text {onset }}$ & $\mathbf{T}_{\max }$ & Sample & $\mathbf{T}_{\text {onset }}$ & $\mathbf{T}_{\max }$ \\
\hline RTM6 neat & $327 \pm 5$ & $389 \pm 4$ & & & \\
\hline ATH 5\% & $332 \pm 3$ & $395 \pm 3$ & ZB 5\% & $342 \pm 3$ & $380 \pm 2$ \\
\hline ATH 10\% & $325 \pm 5$ & $393 \pm 3$ & ZB 10\% & $348 \pm 4$ & $382 \pm 4$ \\
\hline ATH 20\% & $321 \pm 5$ & $392 \pm 4$ & ZB 20\% & $352 \pm 5$ & $388 \pm 3$ \\
\hline ATH 30\% & $360 \pm 4$ & $411 \pm 2$ & ZB 30\% & $368 \pm 3$ & $418 \pm 5$ \\
\hline ATH 40\% & $368 \pm 5$ & $413 \pm 3$ & ZB 40\% & $379 \pm 3$ & $426 \pm 4$ \\
\hline
\end{tabular}


sary to add a high weight content of filler to induce an active retardant effect to the degradation process of the hosting material.

In the case of $\mathrm{ATH}$, the presence of the additives increases the onset temperature due to the decomposition reaction $\left[2 \mathrm{Al}(\mathrm{OH})_{3} \rightarrow \mathrm{Al}_{2} \mathrm{O}_{3}+3 \mathrm{H}_{2} \mathrm{O}\right.$ ] which takes place between 220 and $400^{\circ} \mathrm{C}$. ATH decomposition is an endothermic reaction, which, ATH absorbs about $1 \mathrm{~kJ} / \mathrm{g}$ of heat. The main endothermic peak of the reaction occurs at about $300^{\circ} \mathrm{C}$, which means that the reaction is absorbing the most heat at a temperature below the service degradation temperature level of most polymers. Another important aspect of the reaction is the release of water vapour formed from the hydroxyl group bonded with aluminium. This water is released into the flame hindering the combustion process by diluting the concentration of flammable evolving gases and restricting the access of oxygen through the composite surface. An added benefit of the decomposition reaction is that no toxic or corrosive gases are produced unlike some other flame retardant compounds are present. ATH also operates as a heat sink extending the time to reach the polymer decomposition temperature. ATH has a higher heat capacity than most organic resins, enabling it to absorb heat and promoting a 'cooling' effect of the host polymer. It is believed that another mechanism of ATH is the formation of a refractory layer of $\mathrm{Al}_{2} \mathrm{O}_{3}$ following the decomposition of the ATH. The efficiency of the aluminium oxide layer with the consistency and thickness needed to be an effective thermal barrier is strictly depended upon the ATH content [21]. ZB acts as flame retardant in both condensed and gas phases of the combustion process. At elevated temperatures, this compounds decomposes, releasing crystallization water molecules (about $15 \%$ by weight of water in the temperature range of $290-450^{\circ} \mathrm{C}$ ) which dilutes the concentration of $\mathrm{H}$ radicals and organic volatiles in the flame, reducing its temperature. After decomposition, the residual borate retained in the decomposed polymer will form a vitreous-like layer that slows the permeation of volatile compounds through the surface and restricts them from entering the gas phase [21].

Analysis of onset temperatures evaluated by TGA scans, lead to the main conclusion that both types of fillers do not enhance significantly the start of degradation process below a specific concentration,

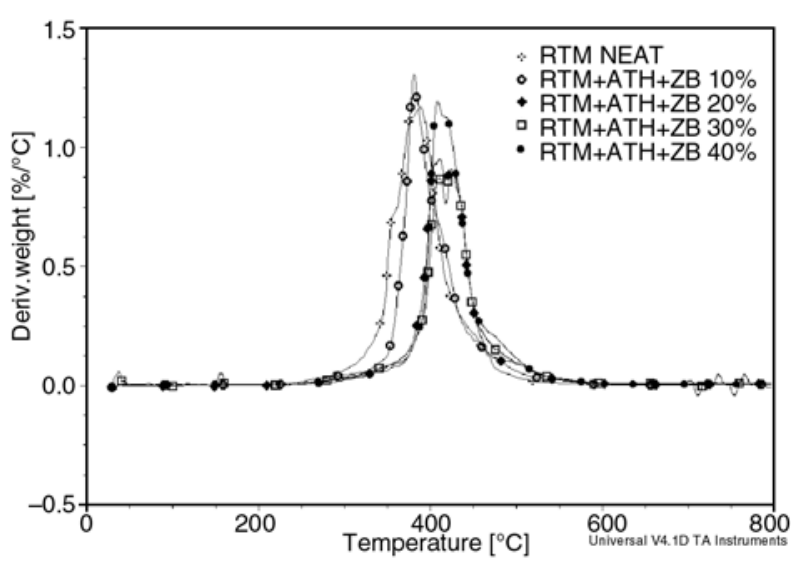

Figure 4. DTG curves of RTM6/ATH/ZB system at different percentage

Table 2. TGA values of treated RTM6 with $\mathrm{ZB}+\mathrm{ATH}$ at different concentrations

\begin{tabular}{|l|c|c|}
\hline \multicolumn{1}{|c|}{ Sample } & $\mathbf{T}_{\text {onset }}\left[{ }^{\circ} \mathbf{C}\right]$ & $\mathbf{T}_{\max }\left[{ }^{\circ} \mathbf{C}\right]$ \\
\hline RTM6 neat & $327 \pm 5$ & $389 \pm 4$ \\
\hline RTM6+ZB+ATH (10\%wt) & $345 \pm 4$ & $381 \pm 4$ \\
\hline RTM6+ZB+ATH (20\%wt) & $352 \pm 4$ & $417 \pm 4$ \\
\hline RTM6+ZB+ATH (30\%wt) & $365 \pm 3$ & $428 \pm 3$ \\
\hline RTM6+ZB+ATH (40\%wt) & $375 \pm 5$ & $434 \pm 5$ \\
\hline
\end{tabular}

as expected. Different observations can be made by analysing the TGA results of RTM6 and a combination amount of $\mathrm{ZB}$ and ATH. The synergy between the ZB and ATH was investigated on four different percentages $(10,20,30$ and $40 \%$ w/w with 1:1 ratio in mass) and the corresponding DTG curves are reported in Figure 4. Table 2 reports the onset and maximum degradation temperatures for all concentrations considered of ATH/ZB loaded samples according to the thermogravimetry. It can be noticed that small variations are found for both parameters if the filler content is lower than $20 \% \mathrm{w} / \mathrm{w}$ (i.e. $10 \% \mathrm{w} / \mathrm{w}$ of ATH and $10 \% \mathrm{w} / \mathrm{w}$ of $\mathrm{ZB}$ ); whereas, for higher weight content (i.e. higher than $15 \% \mathrm{w} / \mathrm{w}$ for each filler) appreciable increase of both temperature levels are found. The combination of these two types of flame retardant reduces the overall concentration level needed to achieve a higher flammability resistance; thus, minimising the risk of adverse effects, such as mechanical property degradation and density increase of the hosting materials. The analysis of experimental TGA and DTG curves with a law of mixture based model, hereby referred as calculated curves, could be very useful to proof the synergistic effect of flame retardancy associated with a combined amount respect to the percentage used of stand- 

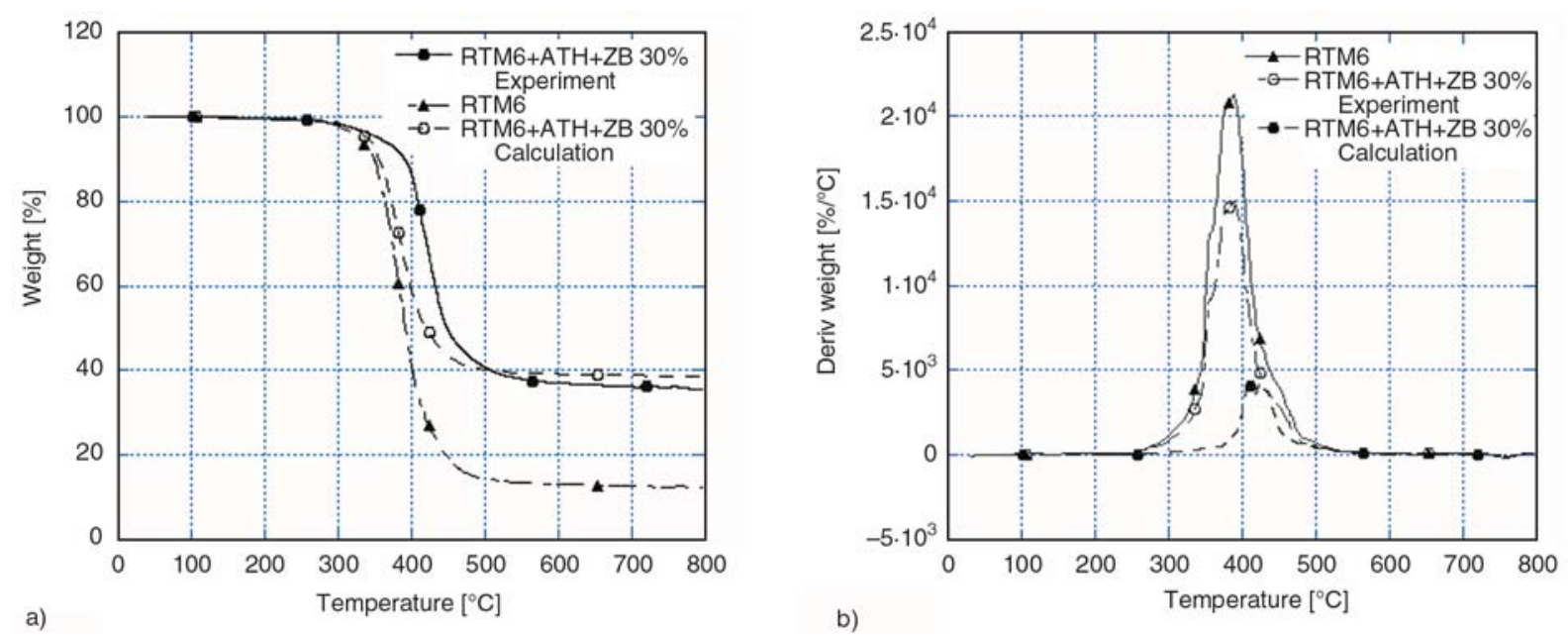

Figure 5. Experimental and calculated TGA (a) and DTG (b) curves for $30 \mathrm{wt} \%$ RTM6/ATH/ZB

alone filler. Calculated and experimental TG-DTG curves have been superimposed in Figure 5 for the $30 \% \mathrm{w} / \mathrm{w} \mathrm{ZB} / \mathrm{ATH}$ amount. Experimental curves are shifted to higher temperatures if compared with their corresponding calculated curves; therefore a superposition effect of flame retardancy due to the presence of each filler is not able to model accurately the experimental results. A synergic mechanism due to the combined amount of fillers can be assumed to occur on the degradation behaviour of the overall loaded system. Similar results were also obtained for all other considered total concentrations, leading to analogous results. The synergistic effect due to the presence of both, ZB and ATH, is quantified by substantial the increase of the onset and maximum degradation temperatures, respectively of 50 and $40^{\circ} \mathrm{C}$ for the highest total percentage compared with the neat epoxy system.

It can be concluded that the addition of $\mathrm{ZB}$ and ATH synergistically retards the degradation behaviour of neat matrix system enhancing the

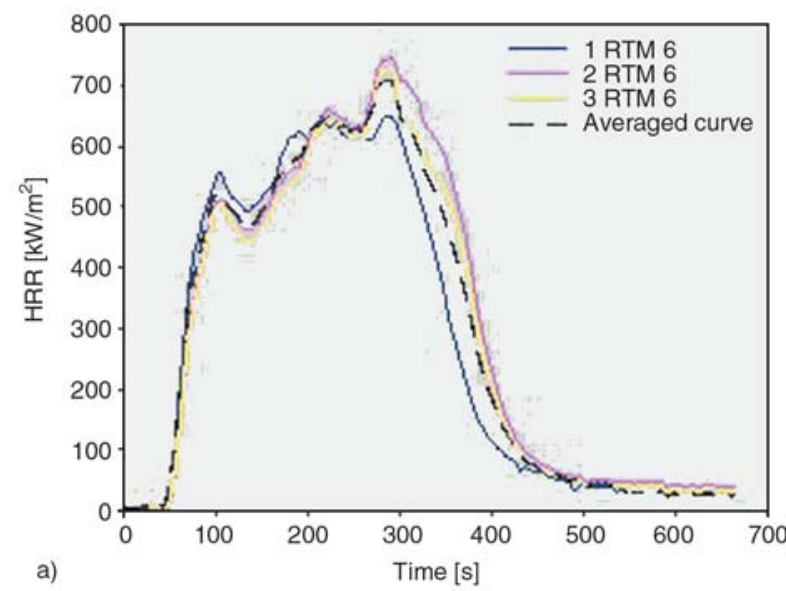

flame retardancy of the overall hosting system at lower concentration respect to the stand alone filler loading.

\subsection{Cone calorimeter test}

Cone calorimeter represents a small-scale testing configuration which provides important correlating parameters with real fire scenario; data obtained from cone calorimeter can provide plentiful information on fire scenario behaviour of a specific material [22, 23]. Figures $6 a$ and $6 b$ report the HRR curves over three different tests, respectively for the neat epoxy and loaded systems along with their average. The values provided by cone calorimeter are mainly: Time To Ignition (TTI), which corresponds to the period that a combustible material can withstand when exposure to a constant radiant heat flux before igniting and undergoing sustained flaming combustion; Heat Release Rate peak (PHRR) and average (HRR average) are a quantitative

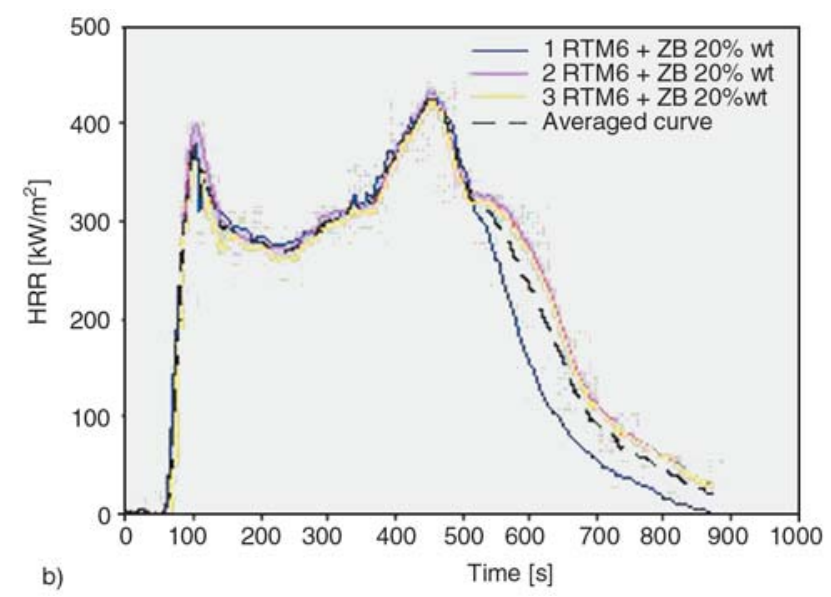

Figure 6. HRR curves for neat epoxy (a) and RTM6 loaded with $20 \%$ w/w of zinc borate (b) 
Table 3. Main cone calorimeter parameters evaluated for RTM6 epoxy with ZB and ATH at different concentrations

\begin{tabular}{|l|c|c|c|c|c|}
\hline \multicolumn{1}{|c|}{ Sample } & $\begin{array}{c}\text { TTI } \\
{[\mathbf{s}]}\end{array}$ & $\begin{array}{c}\Delta \text { TTI } \\
{[\mathbf{s}]}\end{array}$ & $\begin{array}{c}\text { PHRR } \\
{\left[\mathbf{k W / \mathbf { m } ^ { 2 } ]}\right.}\end{array}$ & $\begin{array}{c}\text { HRR Average } \\
{\left[\mathbf{k W} / \mathbf{m}^{2}\right]}\end{array}$ & $\begin{array}{c}\Delta \text { PHRR } \\
{\left[\mathbf{k W} / \mathbf{m}^{2}\right]}\end{array}$ \\
\hline RTM6 & $43 \pm 2$ & - & $702 \pm 3$ & $382 \pm 4$ & - \\
\hline RTM6+ZB 5\% & $44 \pm 5$ & 5 & $682 \pm 2$ & $354 \pm 3$ & 20 \\
\hline RTM6+ZB 10\% & $48 \pm 4$ & 1 & $523 \pm 3$ & $265 \pm 2$ & 179 \\
\hline RTM6+ZB 20\% & $49 \pm 3$ & 6 & $428 \pm 2$ & $251 \pm 4$ & 274 \\
\hline RTM6+ZB 30\% & $58 \pm 2$ & 14 & $396 \pm 3$ & $193 \pm 3$ & 306 \\
\hline RTM6+ZB 40\% & $63 \pm 2$ & 20 & $315 \pm 2$ & $148 \pm 2$ & 387 \\
\hline RTM6+ATH 5\% & $33 \pm 6$ & -10 & $815 \pm 4$ & $413 \pm 2$ & -113 \\
\hline RTM6+ATH 10\% & $41 \pm 3$ & 8 & $728 \pm 4$ & $383 \pm 2$ & -26 \\
\hline RTM6+ATH 20\% & $52 \pm 3$ & 9 & $510 \pm 5$ & $368 \pm 3$ & 192 \\
\hline RTM6+ATH 30\% & $64 \pm 2$ & 21 & $468 \pm 5$ & $324 \pm 1$ & 234 \\
\hline RTM6+ATH 40\% & $93 \pm 2$ & 50 & $453 \pm 2$ & $193 \pm 2$ & 249 \\
\hline RTM6+ZB+ATH 10\% & $52 \pm 2$ & 9 & $679 \pm 3$ & $337 \pm 2$ & 23 \\
\hline RTM6+ZB+ATH 20\% & $52 \pm 3$ & 9 & $468 \pm 2$ & $285 \pm 3$ & 234 \\
\hline RTM6+ZB+ATH 30\% & $55 \pm 3$ & 12 & $431 \pm 1$ & $249 \pm 2$ & 271 \\
\hline RTM6+ZB+ATH 40\% & $87 \pm 2$ & 44 & $437 \pm 4$ & $74 \pm 3$ & 265 \\
\hline
\end{tabular}

measures of the amount of thermal energy released by a material per unit area when exposed to a fire radiating at constant heat flux (or temperature).

The cone calorimeter data reported in Table 3 are averaged over three replicate experiments. The HRR value is considered the single most important fire reaction property as it represents the most valuable indicator of the fire hazard for a combustible material.

For the RTM6/ZB compound, data show that the presence of the filler at 5, 10 and $20 \% \mathrm{w} / \mathrm{w}$ does not change substantially neither the time to ignition or the heat release rate peak values. Instead, the presence of zinc borate at higher concentrations (30, $40 \% \mathrm{w} / \mathrm{w})$ improves flame retardant behaviour of the neat resin system as supported by the recorded values of PHRR and HRR average which increase respectively by 15 and $20 \mathrm{~kW} / \mathrm{m}^{2}$.

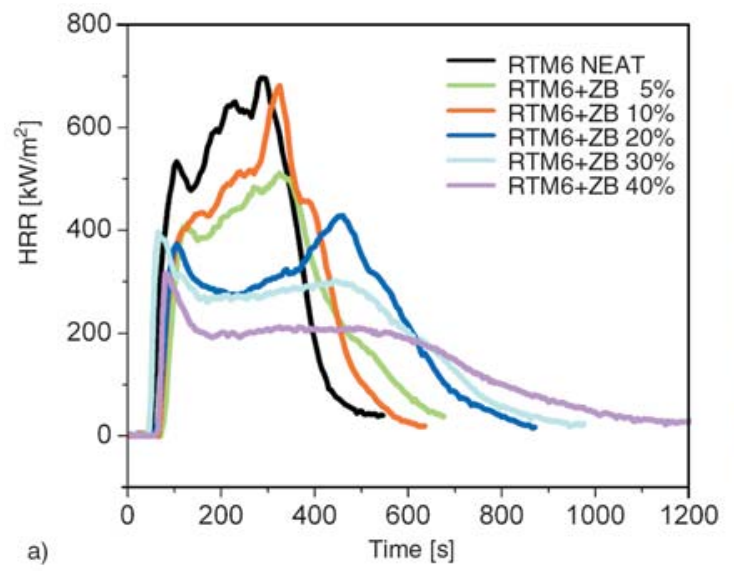

The accentuate peak for the ZB 5\% w/w curve, around $300 \mathrm{~s}$, could be attribute to a local instability of the heat flux during the test which lead to a wider cracked area and therefore, a localised combustion growth. In Figure 7a the HRR curves of RTM6/ZB are characterised by an increased time period up to $1200 \mathrm{~s}$ in the case of $40 \% \mathrm{w} / \mathrm{w}$ content, with a progressive flatness of the curve height at highest content. Decreasing values for the PHRR and HRR average may be correlated with the decomposition of the filler and the formation of a protective glassy char layer over the surface of sample, during the combustion process (Figure 7b). The consistency of this formed layer, inevitably, reduces oxygen absorption and limits the permeation of volatile compounds through the surface of the fired system.

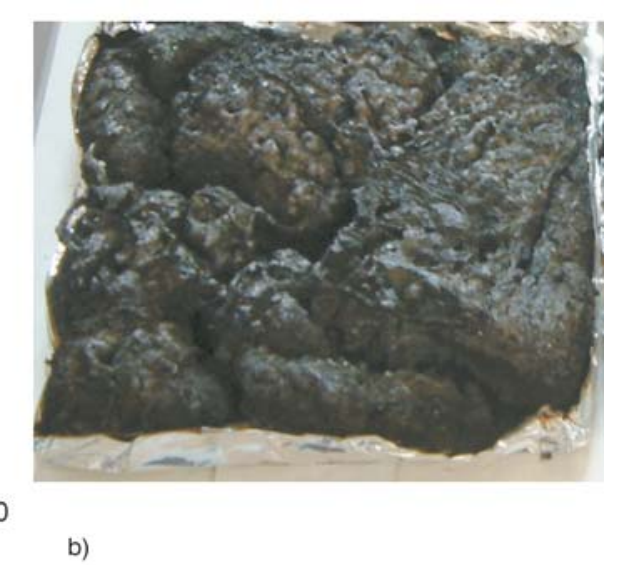

Figure 7. HRR curves of RTM6/ZB at different concentrations (a) and RTM6/ZB at 40\% w/w residue (b) 

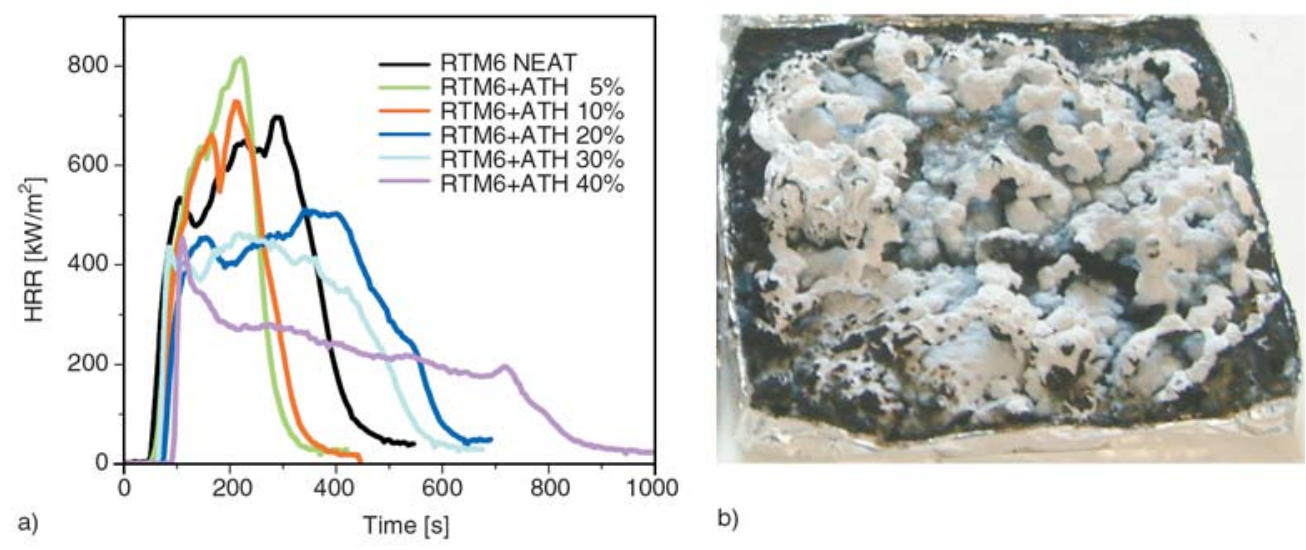

Figure 8. HRR curves of RTM6/ATH at different concentrations (a) and RTM6/ATH at 40\% w/w residue (b)

In the case of ATH filler, it was found that the presence of the micro-sized particles has a detrimental effect at lower concentrations compared with the neat epoxy system (Figure 8a). The two curves, in fact, are characterised by a higher peak value and a slight left shifting, probably due to the presence of filler which breaks the continuity of the hosting system providing a more opened morphology of the char for the propagation of the flame. Analysis of cone calorimetry results indicates that the HRR peak of the RTM6/ATH system is reduced from 815 to $510 \mathrm{~kW} / \mathrm{m}^{2}$, respectively for the 5 and $20 \% \mathrm{w} / \mathrm{w}$ and this value is further reduced with rising of filler concentration to $453 \mathrm{~kW} / \mathrm{m}^{2}$ for the maximum content of $40 \% \mathrm{w} / \mathrm{w}$. The filler effect on HRR averaged values is also very noticeable varying of about $50 \%$ for the highest filler content $\left(193 \mathrm{~kW} / \mathrm{m}^{2}\right)$ compared with the unloaded epoxy $\left(382 \mathrm{~kW} / \mathrm{m}^{2}\right)$. For ATH content higher than $20 \% \mathrm{w} / \mathrm{w}$ the material behaviour is affected by the presence of the filler with more evidence: flattening

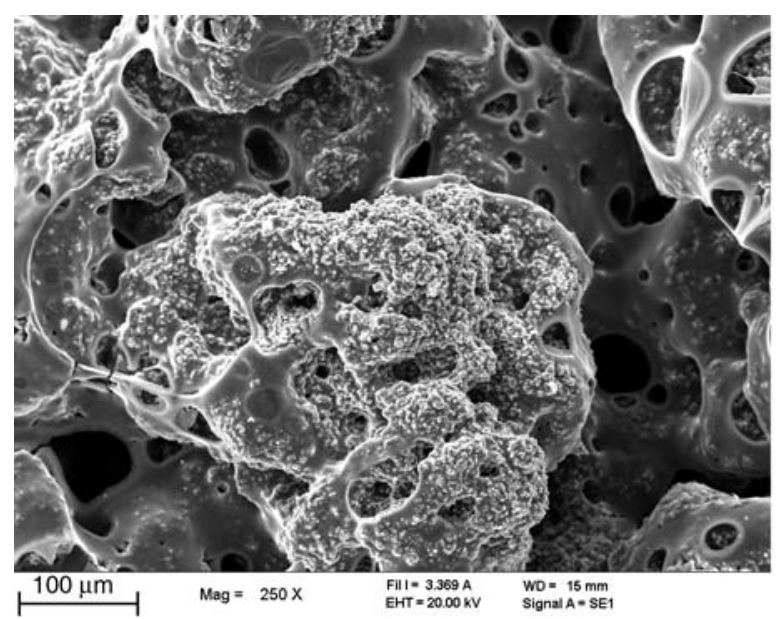

a) the curve and reducing the averaged HRR. In Figure $8 \mathrm{~b}$ the image of the residue $40 \%$ w/w RTM6/ ATH system with the whitish surface characteristic of the aluminium trihydroxide is reported. A visual inspection of the final residual sample reports the presence of the char layer (Figures $7 \mathrm{~b}$ and $8 \mathrm{~b}$ ) characterised by a different morphology. Analysis of SEM micrographs on residual of system of epoxy resin, zinc borate and aluminium trihydroxide indicates that char topography varies from a compact like-amalgam structure for the RTM6/ZB (Figure 9 a) to a granular porous-like structure characterized by very small particles of additive along with some residual carbon from the resin for the ATH mixture (Figure 9b).

Different conclusions can be drawn in the case of ATH and ZB mixture filler content. The synergistic effect of these two additives becomes effective with a weight content of both fillers higher than $10 \%$. In fact, the averaged HHR undergoes a slight drop from $382 \mathrm{~kW} / \mathrm{m}^{2}$ for the epoxy resin to

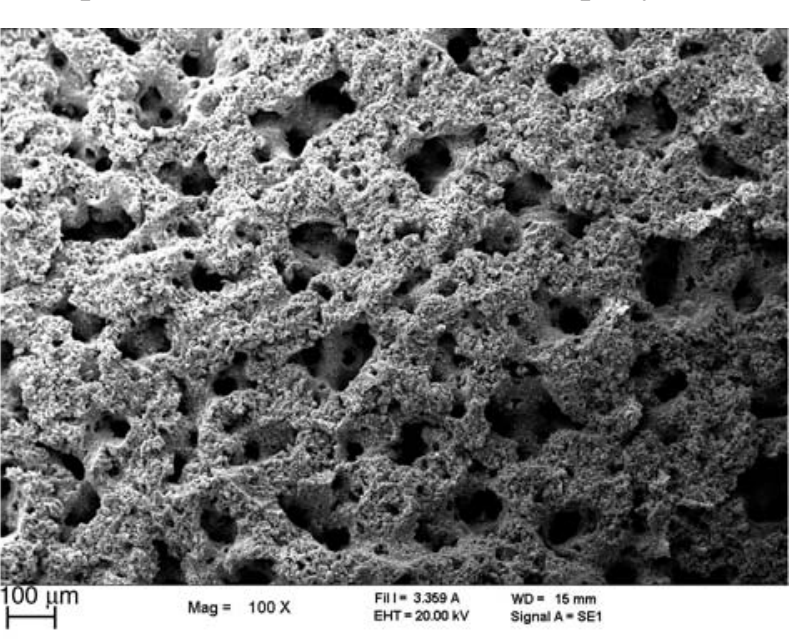

b)

Figure 9. SEM micrographs of residual samples of RTM6/ZB 20 wt\% (a)and of RTM6/ATH 20 wt\% (b) 

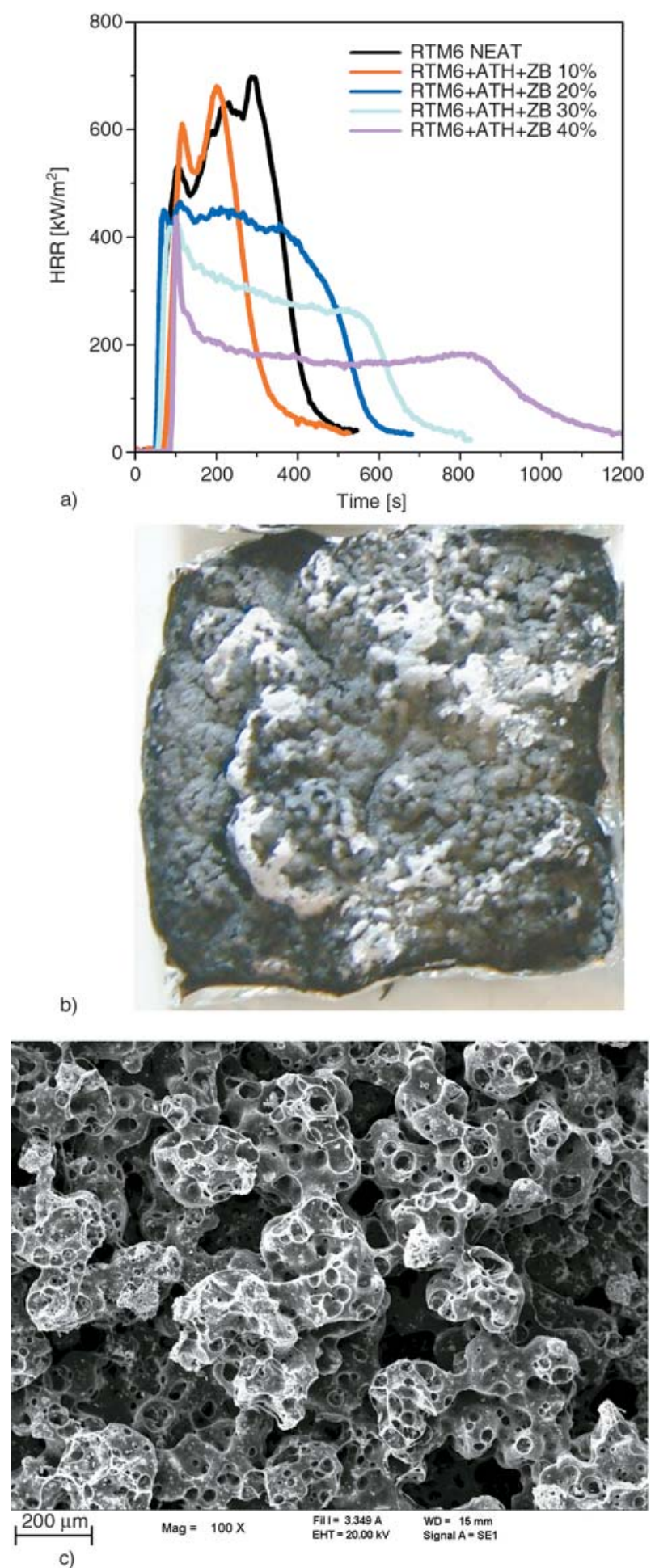

Figure 10. HRR curves of RTM6/ZB/ATH system at different concentrations (a), RTM6/ZB/ATH system residue (b) and SEM of residual samples of RTM6/ZB/ATH system (c)

$285 \mathrm{~kW} / \mathrm{m}^{2}$ for system RTM6/ZB/ATH $20 \% \mathrm{w} / \mathrm{w}$, with a further reduction to 249 and $74 \mathrm{~kW} / \mathrm{m}^{2}$, respectively for the 30 and $40 \%$ w/w of RTM6/ZB/
ATH (Figure 10a). This indicates that the concentration of the each filler can be lowered in the case of ATH/ZB mixture loading if compared with the corresponding single filler system due to the synergistic effect associated with the presence of both additives. Comparing the $\triangle T$ TTI and the HRR average values for RTM6/ZB 20\% w/w, RTM6/ATH $20 \% \mathrm{w} / \mathrm{w}$ and RTM6/ZB/ATH system at $40 \% \mathrm{w} / \mathrm{w}$, the filler synergy improves significantly the flame retardancy, respectively from 6 to 9 to $44 \mathrm{~s}$; and from 251 to 368 to $74 \mathrm{~kW} / \mathrm{m}^{2}$. An optical image and an SEM micrograph of residual samples of RTM6/ZB/ATH are reported respectively in Figures $10 \mathrm{~b}$ and $10 \mathrm{c}$. The char is characterised by an amalgam structure due to $\mathrm{ZB}$ filler and a porous whitish morphology typical of the ATH residue is clearly showed by the SEM photo.

\section{Conclusions}

The synergistic effect of zinc borate and aluminium trihydroxide on flammability behaviour of monocomponent epoxy resin has been studied in this work. Cone calorimeter experiments and results, obtained by thermogravimetric analysis, report clearer evidence that content of zinc borate and aluminium trihydroxide higher that $20 \% \mathrm{w} / \mathrm{w}$ makes the neat resin system resistant to flame. Moreover a combination of the two fillers, at lower specific content, will affect synergistically the flammability behaviour of the neat system minimising the risk of adverse effects of original materials. Characteristic parameters, obtained by cone calorimeter tests, such as PHRR, HRR average and TTI reach higher values, indicating improved fire behaviour. The synergistic effect of zinc borate with aluminium trihydroxide on the RTM6 epoxy resin can be reasonably proved not only comparing the TGA experiential curve with a mixture law based model but also analysing the cone results related with the $20 \% \mathrm{w} / \mathrm{w}$ combined loads. Scanning electron micrographs indicate that the synergist flame retardant effects of these additives results from the excellent quality of char which compromises the $\mathrm{ZB}$ and ATH char morphology enduring the oxidation at high temperatures slowing, at same time, the degradation of epoxy resin. 


\section{References}

[1] Giùdice C. A., Benitez J. C: Zinc borates as flameretardant pigments in chlorine-containing coatings. Progress in Organic Coatings, 42, 82-88 (2001). DOI: $10.1016 / \mathrm{S} 0300-9440(01) 00159-\mathrm{X}$

[2] Nazare S., Kandola B. K., Horrocks A. R.: Smoke, $\mathrm{CO}$, and $\mathrm{CO}_{2}$ measurements and evaluation using different fire testing techniques for flame retardant unsaturated polyester resin formulations. Journal of Fire Sciences, 26, 215-242 (2008). DOI: $\underline{10.1177 / 0734904107087818}$

[3] Wu Z., Shu W., Hu Y.: Synergist flame retarding effect of ultrafine zinc borate on LDPE/IFR system. Journal of Applied Polymer Science, 103, 3667-3674 (2007).

DOI: $10.1002 / a p p .25575$

[4] Maurer O.: New reactive, halogen-free flame retardant system for epoxy resins. Polymer Degradation and Stability, 88, 70-73 (2005).

DOI: $10.1016 /$ j.polymdegradstab.2004.01.027

[5] Shen K. K., Kochesfahani S., Jouffret F.: Zinc borates as multifunctional polymer additives. Polymers for Advanced Technology, 19, 469-474 (2008).

DOI: $10.1002 /$ pat.1119

[6] Bourbigot S., Le Bras M., Leeuwendal R., Shen K. K., Schubert D.: Recent advances in the use of zinc borates in flame retardancy of EVA. Polymer Degradation and Stability, 64, 419-425 (1999).

DOI: $10.1016 / \mathrm{S} 0141-3910(98) 00130-X$

[7] Kim S.: Flame retardancy and smoke suppression of magnesium hydroxide filled polyethylene. Journal of Polymer Science Part B: Polymer Physics, 41, 936944 (2003).

DOI: $10.1002 /$ polb.10453

[8] Ning Y., Guo S.: Flame-retardant and smoke-suppressant properties of zinc borate and aluminium trihydrate-filled rigid PVC. Journal of Applied Polymer Science, 77, 3119-3127 (2000).

DOI: $10.1002 / 1097-4628(20000929) 77: 14<3119:$ : AID-APP130>3.0.CO;2-N

[9] Wu S., Cong P., Yu J., Luo X., Mo L.: Experimental investigation of related properties of asphalt binders containing various flame retardants. Fuel, 85, 12981304 (2006).

DOI: $10.1016 /$ j.fuel.2005.10.014

[10] Bourbigot S., Le Bras M., Duquesne S., Rochery M.: Recent advances for intumescent polymers. Macromolecular Materials and Engineering, 289, 499-511 (2004).

DOI: $\underline{10.1002 / m a m e .200400007}$

[11] Bourbigot S., Duquesne S.: Fire retardant polymers: Recent developments and opportunities. Journal of Materials Chemistry, 17, 2283-2300 (2007). DOI: $10.1039 / \mathrm{b} 702511 \mathrm{~d}$

[12] Griffiths B.: SETEC 01/-06: The SAMPE Europe Toulouse Conference. High Performance Composites, 14(11), 22-23 (2006).
[13] Carpentier F., Bourbigot S., Le Bras M., Delobel R., Foulon M.: Charring of fire retarded ethylene vinyl acetate copolymer-magnesium hydroxide/zinc borate formulations. Polymer Degradation and Stability, 69, 83-92 (2000).

DOI: $\underline{10.1016 / S 0141-3910(00) 00044-6}$

[14] Genovese A., Shanks R. A.: Structural and thermal interpretation of the synergy and interactions between the fire retardants magnesium hydroxide and zinc borate. Polymer Degradation and Stability, 92, 2-13 (2007).

DOI: $10.1016 /$ j.polymdegradstab.2006.10.006

[15] Hu Z. S., Dong J. X., Chen G. X.: Study on anti wear and reducing friction additive of nanometer ferric oxide. Tribology International, 31, 355-360 (1998). DOI: $\underline{10.1016 / \mathrm{S} 0301-679 X(98) 00042-5}$

[16] Diagne M., Guèye M., Vidal L., Tidjani A.: Thermal stability and fire retardant performance of photo-oxidized nanocomposites of polypropylene-graft-maleic anhydride/clay. Polymer Degradation and Stability, 89, 418-426 (2005).

DOI: $10.1016 /$ j.polymdegradstab.2005.01.032

[17] Xie R. C., Qu B. J.: Expandable graphite systems for halogen-free flame-retarding of polyolefins. I. Flammability characterization and synergistic effect. Journal of Applied Polymer Science, 80, 1181-1189 (2001). DOI: $10.1002 / a p p .1202$

[18] Shen K. K., Olson E.: Recent advances on the use of borates as fire retardants in polymers. Sixteenth Annual BCC Conference on Flame Retardancy, Stamford, USA, 286-288 (2005).

[19] Zhang S., Horrocks A. R.: A review of flame retardant polypropylene fibres. Progress in Polymer Science, 28, 1517-1538 (2003).

DOI: 10.1016/j.progpolymsci.2003.09.001

[20] Samyn F., Bourbigot S., Duquesne S., Delobel R.: Effect of zinc borate on the thermal degradation of ammonium polyphosphate. Thermochimica, 456, 134-144 (2007).

DOI: $\underline{10.1016 / \text { j.tca.2007.02.006 }}$

[21] Mouritz A. P., Gibson A. G.: Fire properties of polymer composites materials. Springer, Berlin (2006).

[22] Franchini M. C., Fabbri P., Frache A., Ori G., Messori M., Siligardi C., Ricci A.: Bentonite-based organoclays as innovative flame retardant agents for SBS copolymer. Journal of Nanoscience and Nanotechnology, 8, 6316-6324 (2008). DOI: 10.1166/jnn.2008.379

[23] Schartel B., Hull T. R.: Development of fire-retarded materials - Interpretation of cone calorimeter data. Fire and Materials, 31, 327-354 (2007). DOI: $10.1002 /$ fam.949 